\title{
Disseminated petriellidiosis (allescheriasis) in a patient with refractory acute lymphoblastic leukaemia
}

\author{
LY SHIH, N LEE* \\ From the Division of Haematology, Department of Internal Medicine and the *Department of Pathology, \\ Chang Gung Memorial Hospital, 199 Tung-Hwa North Road, Taipei, Taiwan, 105
}

SUMMARY A case of disseminated petriellidiosis is presented. This complication occurred in a patient with refractory acute lymphoblastic leukaemia, who was receiving repeated courses of cytotoxic drugs, antibiotics and prolonged corticosteroid therapy. The diagnosis of infection by Petriellidium boydii was established by pathological and microbiological studies of a specimen obtained at open lung biopsy. The portal of entry was probably through the lung spreading later via the blood stream to the brain, thyroid and kidneys. The present case once again emphasises the importance of specific microbiological identification in definitive diagnosis. To our knowledge, only three cases of disseminated petriellidiosis have been reported and this case appears to be the first case with renal involvement.

Recent advances in the treatment of acute leukaemia have contributed to prolonged survival, but these have been offset by a substantial increase in the frequency of opportunistic fungal infections. ${ }^{12}$ Petriellidium (Allescheria) boydii is well known as a causative agent of Madura foot in the United States. ${ }^{3}$ Extracutaneous sites of infection with this organism are relatively infrequent and disseminated infection is extremely rare.

The purpose of this report is to describe a patient with refractory acute lymphoblastic leukaemia complicated by a disseminated petriellidiosis. To our knowledge, this is only the fourth case of disseminated petriellidiosis ever reported in the English literature.

\section{Case report}

A 20-year-old male Taiwanese was first seen on 21 December 1980 with the complaints of fatigue, exertional dyspnoea and lower sternal pain. Diagnosis of acute lymphoblastic leukaemia was established after bone marrow and blood examination. Complete remission was achieved on 28 January 1981 after induction therapy with vincristine and prednisolone which was followed by prophylactic cranial irradiation and intrathecal methotrexate. Remission was maintained with 6-mercaptopurine and oral methotrexate. "Pulses" of vincristine and prednisolone were given at three monthly intervals for

Accepted for publication 1 September 1983 reinforcement. He continued on this regimen until 27 February 1982 when he had his first bone marrow relapse. A second remission was achieved with adriamycin, vincristine and prednisolone, and then followed by the same maintenance therapy. After a second marrow relapse on 30 June 1982, remission was again induced by adriamycin, vincristine and prednisolone. Unfortunately the remission only lasted four weeks. A further marrow relapse occurred at the end of August 1982 and there was no subsequent remission despite various courses of chemotherapy consisting of adriamycin, vincristine, cytosine arabinoside, cyclophosphamide, high dose methotrexate and prednisolone. During the course, there were several episodes of infections including upper respiratory tract, oropharynx and perianal infections, which were all successfully treated by antibiotics.

On 2 December 1982 he was readmitted for treatment of his refractory leukaemia. Physical examination on admission was within normal limits except for a marked sternal tenderness. Adriamycin and cytosine arabinoside were reinstituted. Profound granulocytopenia and high fever developed on 13 December. Empirical antibiotics with carbenicillin and tobramycin was given. Fever resolved on 15 December but again arose to $39 \cdot 4^{\circ} \mathrm{C}$ two days later, associated with cough and occasional headache during febrile episodes; cefamandole was then added. Chest $x$-ray examination showed bilateral upper pulmonary infiltrates with evidence of cavitation in the left upper lung (Fig. 1). The roentgenogram in 


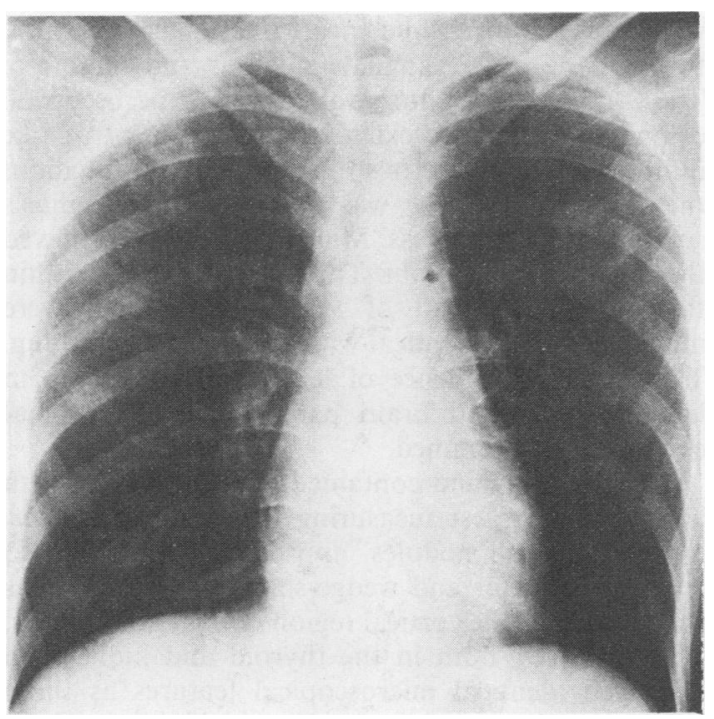

Fig. 1 Chest $x$-ray showing bilateral upper infiltrates with a cavity in the left upper lung.

October revealed clear lung fields. Urine culture and several blood cultures were unrevealing. Sputum smears and cultures for acid fast bacilli or other bacteria and fungi were all negative. The patient remained persistently febrile. Blood streaked sputum and left pleuritic pain developed on 21 December and the follow-up chest film showed progression of pulmonary lesions. Open lung biopsy from the left upper lobe was performed on 24 December. Pathological examination revealed suppurative inflammation with presence of branching septate fungal hyphae in the necrotic lung tissue and overlying pleura. The findings were initially thought to be consistent with aspergillosis. Subsequently the fungus was identified on culture as Petriellidium boydii. Blurred vision, weakness of the left extremities and left central type facial palsy developed on 27 December. A lumbar puncture revealed an opening pressure of $80 \mathrm{~mm} \mathrm{H}_{2} \mathrm{O}$. The cerebrospinal fluid showed $81 \times 10^{6} / 1$ with $93 \%$ segmented cells, $6 \%$ monocytes and $1 \%$ lymphocytes, glucose was $56 \mathrm{mg} / \mathrm{dl}$ (simultaneous blood glucose $95 \mathrm{mg} / \mathrm{dl}$ ) and protein was $51 \mathrm{mg} / \mathrm{dl}$. No leukaemic cells were found. Smears for acid-fast bacilli, Gram's stain, potassium hydroxide and India ink preparations were negative, as were cultures for bacteria and fungi of cerebrospinal fluid. A computerised tomograph scan of the brain showed non-enhancing hypodensity at right basal ganglia, right thalamic and right deep frontal regions. Unfortunately his neurological condition deteriorated rapidly and he developed uncontrollable seizures and coma. He died on 30 December.

\section{POSTMORTEM FINDINGS}

At necropsy, there was a $150 \mathrm{ml}$ serous pleural effusion in each pleural cavity and a $100 \mathrm{ml}$ yellowish clear pericardial effusion. Adhesions were found in the right upper pleural space, between left upper and lower lobes of lung and adjacent pleurae. On sectioning, right upper lung contained a $2.5 \mathrm{~cm} \times 2.5 \mathrm{~cm}$ cavity which was filled with laminated yellowish-black pieces of fungus ball-like mass. An abscess measuring $2 \mathrm{~cm} \times 1.5 \mathrm{~cm}$ was present in the left upper lung and contained soft grey material. Microscopically, the right intracavitary mass consisted of concentric rings of tangled hyphal strands and spores (Fig. 2). The left lung abscess was lined by granulation tissue and contained clumps of branching septate hyphae bearing occasional terminal brownish conidia along with necrotic debris and inflammatory cells. The fungi were also found in the abscess wall as well as in the blood vessel wall. The fungi were seen faintly in haematoxylin and eosin stained preparations, but were better demonstrated in periodic acid-Schiff and Gomori methenamine silver nitrate stained preparations. Aspergillus conidiophores were not observed. Fungal involvement of pleura with fibrinoid pleuritis was noted. No leukaemic infiltration of pulmonary parenchyma was seen. Foci of bronchopneumonia were present. The remainder of the lung was congested and oedematous.

The brain weighed $1450 \mathrm{~g}$ and the right cerebral hemisphere was swollen. There was a large abscess, measuring $3 \mathrm{~cm} \times 2 \mathrm{~cm} \times 4.5 \mathrm{~cm}$, extending from the

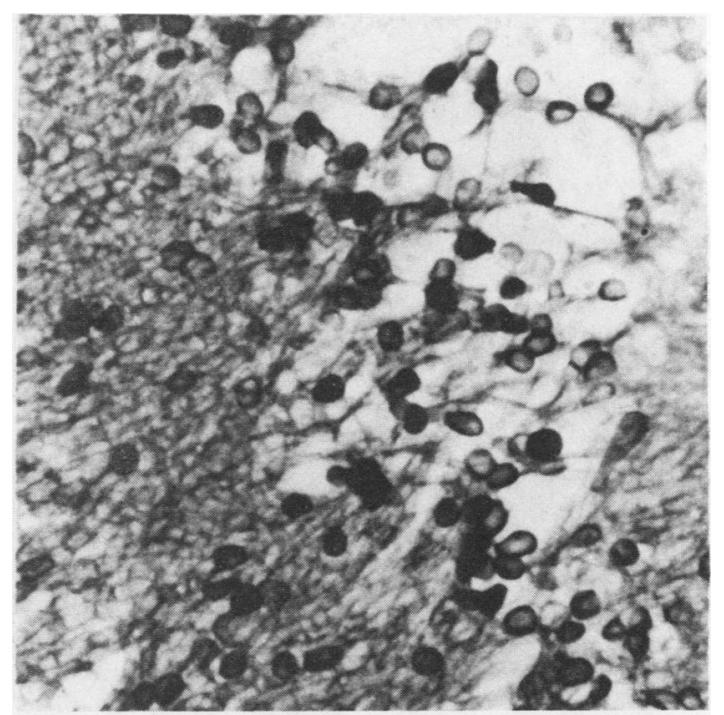

Fig. 2 Section of the mass in the cavity in the right upper lung showing clumps of septate hyphae and spores. Periodic acid-Schiff stain $\times 400$. 


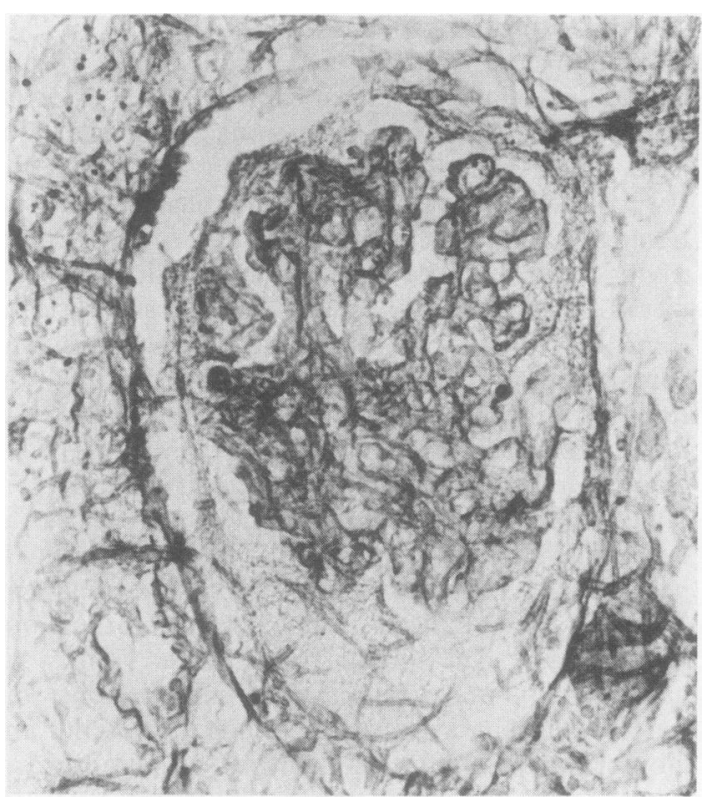

Fig. 3 A single glomerulus showing fungal invasion. Gomori methenamine silver stain $\times 200$.

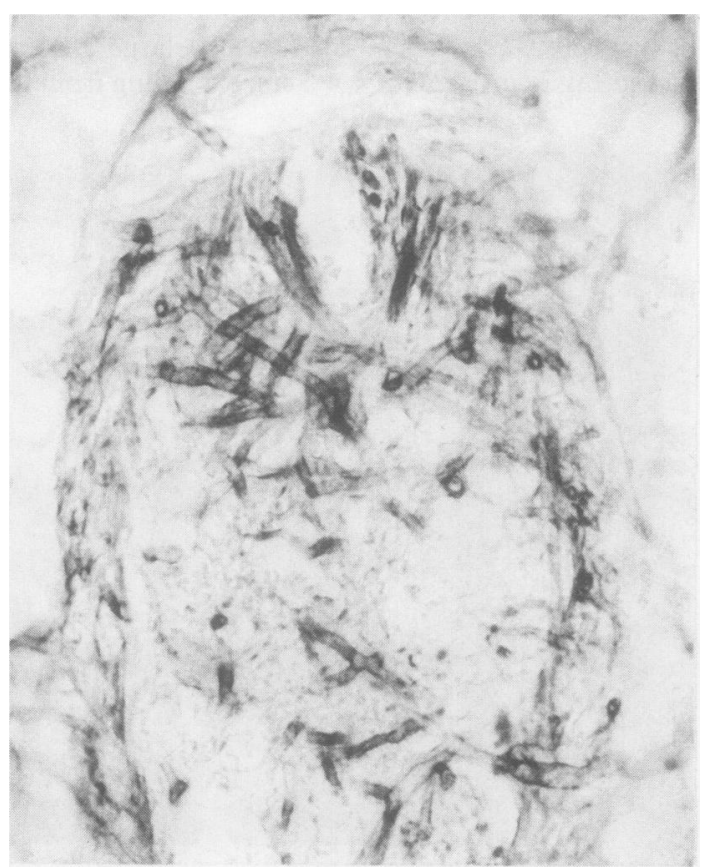

Fig. 4 Renal blood vessel showing fungal invasion of vessel wall and lumen. Gomori methenamine silver stain $\times 400$. right lower frontal lobe (near anterior commissure) through the basal ganglia, thalamus and midbrain. The abscess was not walled off. Microscopical examination revealed extensive necrosis, neutrophilic infiltration and numerous fungi scattered throughout the abscess. There was mild reactive gliosis surrounding the abscess. Many blood vessels showed the presence of thrombi. The fungi were seen within the lumen and wall of vessels. The fungi were morphologically identical with those seen in the lung. There was no evidence of leukaemic infiltration in leptomeninges and brain parenchyma. The spinal cord was not examined.

The thyroid gland contained multiple tiny whitish lesions, the largest measuring $0.7 \mathrm{~cm}$ in diameter. Many yellowish nodules, approximately $0.5 \mathrm{~cm}$ to $1 \mathrm{~cm}$ in diameter and wedge-shaped infarcted areas were found on the cortical region of bilateral kidneys. The abscesses, both in the thyroid and kidneys all displayed identical microscopical features as those seen in the lung and brain. Fungal invasion of the glomeruli and renal blood vessels was well demonstrated (Figs. 3 and 4).

The gross findings in other organs were unremarkable. Microscopically, the bone marrow, bilateral adrenals, bilateral kidneys and spleen were infiltrated by leukaemic cells.

For legal reasons, at least eight hours must elapse from the time of death before a necropsy may be carried out. Bacteria were grown in large numbers from necropsy material taken from heart blood, lung and the kidney abscess. The heavy bacterial overgrowth inhibited fungal isolation. The brain was not suitable for culture due to previous formalin fixation and a culture of the thyroid abscess was not obtained.

\section{MYCOLOGY}

The lung biopsy tissue was cultured on Sabouraud's dextrose agar at room temperature. White to lightgrey colonies were noted after three days' incubation, which later became smoky-grey with a dark brown on the reverse side. Microscopical examination using lactophenol cotton blue stain of the fungi in the original isolates and their subcultures revealed branching septate hyphae bearing brownish ovoid conidia at the ends or on short sides of conidiophores (Fig. 5). The conidia measuring 3-7 $\mu \mathrm{m} \times 6-10 \mu \mathrm{m}$ in size, usually occurred singly, but occasionally in groups of 2 to 3 . The hyphae measured 1-5 $\mu \mathrm{m}$ in width. The initial isolates were those of the asexual form, Monosporium apiospermum. After three-month incubation on Sabouraud's agar, dark brown, thin-walled perithecia containing large numbers of brown elliptical ascospores were produced (Fig. 6), characteristic of sexual form of Allescheria (Petriellidium) boydii. The 


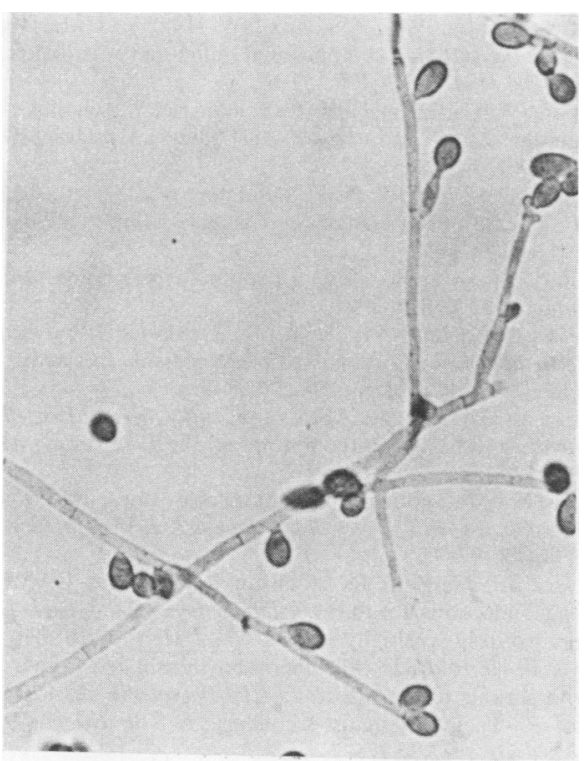

Fig. 5 Branching septate hyphae with terminal or lateral conidia from slide culture grown on Sabouraud dextrose agar. Lactophenol cotton blue preparation $\times 400$.

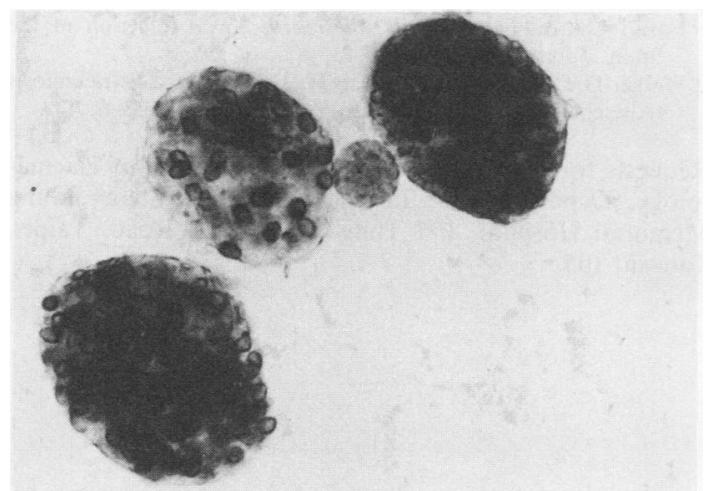

Fig. 6 Perithecia containing ascospores $\times 200$.

perithecia, measuring 25 to $150 \mu \mathrm{m}$ in diameter, when ruptured, released ascospores which were quite constant in size, averaging $3.5 \mu \mathrm{m} \times 6.0 \mu \mathrm{m}$.

\section{Discussion}

Monosporium apiospermum and Petriellidium boydii are the asexual and sexual forms of the same fungus respectively. ${ }^{4}$ Malloch has proposed the new genus Petriellidium for the organism. ${ }^{5}$ This fungus usually enters the body by penetrating injury and causes infection in cutaneous and subcutaneous tissues of the foot. Extracutaneous sites of petriellidiosis are rare. We have found 16 reported cases of pulmonary infection which mostly occurred in farmers with underlying structural lung diseases and usually in the non-invasive form of an opportunistic intracavitary mycetoma. ${ }^{6-21}$ Although rarely, this organism has been implicated in sinusitis, ${ }^{22}{ }^{23}$ endophthalmitis, ${ }^{24}$ joint infection, ${ }^{24}$ parotitis, ${ }^{18}$ prostatitis, ${ }^{25}$ pachymeningitis, ${ }^{26}$ and brain abscess. ${ }^{927}$

Almost all seriously invasive petriellidioses have occurred in compromised hosts or in patients with predisposing underlying conditions. Our patient had refractory acute lymphoblastic leukaemia and had received multiple courses of many cytotoxic drugs, prolonged corticosteroid therapy and various systemic antibiotics. He was therefore highly vulnerable to opportunistic fungal infection. In our case the original infection was assumed to have originated in the lung by inhalation and later to have disseminated via the blood stream to the brain, thyroid and kidneys as evidenced by the presence of fungi in the lumen and wall of vessels.

Disseminated petriellidiosis is extremely rare. To our knowledge, only three cases have been reported. The first case was reported by Rosen et $a l^{28}$ in 1965 from Canada in a patient with subacute glomerulonephritis and treated with corticosteroid and azathioprine. Brain and thyroid abscesses caused by $P$ boydii were found at necropsy. Forno and Billingham ${ }^{29}$ subsequently described the second case of probable air borne pulmonary infection with systemic dissemination to the brain and thyroid in a case of steroid-treated systemic lupus erythematosus. The third similar case was reported by Walker $e t a^{30}$ in a renal allograft recipient taking methylprednisolone and azathioprine. Interestingly, brain and thyroid have been involved in all three reported disseminated cases as well as in the present case. All four had received systemic antibiotic therapy and immunosuppressive drugs before the development of the $P$ boydii infection. The case described here is the only case of systemic petriellidiosis in which renal involvement has been demonstrated.

The present case as well as the cases reported by Louria et al, ${ }^{11}$ Arnett and Hatch, ${ }^{16}$ and Walker et $a l^{30}$ would have been diagnosed mistakenly as aspergillosis if culture had not been obtained. While in the cases reported by Winston et $a l^{9}$ and Gluckman $e t$ $a l, 22$ tissue sections initially suggested a diagnosis of phycomycosis. Since $P$ boydii and other mycoses especially the Aspergillus species produce septate hyphae, their appearance in tissue sections alone will not be diagnostic. Appropriate culture is the only reliable means to an accurate diagnosis.

We are grateful to Miss Chu-Lam Wu for technical assistance and Miss Hsiu-Jen Hung for typing the manuscript. 


\section{References}

1 Bodey GP, Bolivar R, Fainstein V. Infectious complications in leukemic patients. Semin Hematol 1982;19:193-226.

${ }^{2}$ Schimpff SC. Infections in patients with acute leukemia. In: Mandell GL, Douglas RG, Bennett JE, eds. Principles and practice of infectious disease. New York: John Wiley and Sons, 1979:2263-78.

${ }^{3}$ Green WO, Adams TE. Mycetoma in the United States. Am J Clin Pathol 1964;42:75-91.

${ }^{4}$ Emmons CW. Allescheria boydii and Monosporium apiospermum. Mycologia 1944;36:188-93.

${ }^{5}$ Malloch D. New concepts in the microascaceae illustrated by two new species. Mycologia 1970;62:727-40.

${ }^{6} \mathrm{Creitz}$ J, Harris HW. Isolation of Allescheria boydii from sputum. Am Rev Tuberc 1955;71:126-30.

7 Tong JL, Valentine EH, Durrance JR, Wilson GM, Fischer DA. Pulmonary infection with Allescheria boydii: Report of a fatal case. Am Rev Tuberc 1958;78:604-9.

${ }^{8}$ Scharyj M, Levene N, Gordon H. Primary pulmonary infection with Monosporium apiospermum: Report of a case with clinical, pathologic and mycologic data. J Infect Dis 1960;106:141-8.

9 Winston DJ, Jordan MC, Rhodes J. Allescheria boydii infections in the immunosuppressed host. Am J Med 1977;63:830-5.

${ }^{10}$ Alture-Werber E, Edberg SC, Singer JM. Pulmonary infection with Allescheria boydii. Am J Clin Pathol 1976;66:1019-24.

${ }^{11}$ Louria DB, Lieberman PH, Collins HS, Blevins A. Pulmonary mycetoma due to Allescheria boydii. Arch Intern Med 1966;117:748-51.

${ }^{12}$ Reddy PC, Christianson CS, Gorelick DF. Larsh HW. Pulmonary monosporosis: An uncommon pulmonary mycotic infection. Thorax 1969;24:722-8.

${ }^{13}$ Rosen P, Adelson HT, Burleigh E. Bronchiectasis complicated by the presence of Monosporium apiospermum and Aspergillus fumigatus. Am J Clin Pathol 1969;52:182-7.

${ }^{14}$ Travis RE, Ulrich EW, Phillips S. Pulmonary allescheriasis. Ann Intern Med 1961;54:141-52.

${ }^{15}$ Hainer JW, Ostrow JH, Mackenzie DWR. Pulmonary monosporosis: Report of a case with precipitating antibody. Chest 1974;66:601-3.

${ }^{16}$ Arnett JC, Hatch HB. Pulmonary allescheriasis: Report of a case and review of the literature. Arch Intern Med 1975;135:1250-3.
${ }^{17}$ Belitsos NJ, Merz WG, Bowersox DW, Hutchins GM. Allescheria boydii mycetoma complicating pulmonary sarcoid. Johns Hopkins Med J 1974;135:259-67.

${ }^{18}$ Rippon JW, Carmichael JW. Petriellidiosis (Allescheriosis): Four unusual cases and review of literature. Mycopathologia 1976;58:117-24.

${ }^{19}$ Bakerspigel A, Wood T, Burke S. Pulmonary allescheriasis: Report of a case from Ontario, Canada. Am J Clin Patho 1977;68:299-303.

${ }^{20}$ Kathuria SK, Rippon J. Non-aspergillus aspergilloma. Am J Clin Pathol 1982;78:870-3.

${ }^{21}$ Severo LC, Londero AT, Picon PD, Rizzon CFC, Tarasconi JC. Petriellidium boydii fungus ball in a patient with active tuberculosis. Mycopathologia 1982;77:13-7.

${ }^{22}$ Gluckman SJ, Ries K, Abrutyn E. Allescheria (Petriellidium) boydii sinusitis in a compromised host. J Clin Microbio 1977;5:481-4.

${ }^{23}$ Hecht R, Montgomerie JZ. Maxillary sinus infection with Allescheria boydii (Petriellidium boydii). Johns Hopkins Med J 1978:142:107-9.

${ }^{24}$ Lutwick LI, Galgiani JN, Johnson RH, Stevens DA. Visceral fungal infections due to Petriellidium boydii ( Allescheria boydii): In vitro drug sensitivity studies. Am J Med 1976;61:632-40.

${ }^{25}$ Meyer E, Herrold RD. Allescheria boydii isolated from a patient with chronic prostatitis. Am J Clin Pathol 1961:35:155-9.

${ }^{26}$ Selby R. Pachymeningitis secondary to Allescheria boydii. $J$ Neurosurg 1972;36:225-7.

${ }^{27}$ Bell WE, Myers MG. Allescheria (Petriellidium) boydii: Brain abscess in a child with leukemia. Arch Neurol 1978;35:386-8.

${ }^{28}$ Rosen F, Deck JHN, Rewcastle NB. Allescheria boydii--Unique systemic dissemination to thyroid and brain. Can Med Assoc $J$ 1965;93:1125-7.

${ }^{29}$ Forno LS, Billingham ME. Allescheria boydii infection of the brain. J Pathol 1972;106:195-8.

${ }^{30}$ Walker DH, Adamec T, Krigman M. Disseminated Petriellidiosis (Allescheriosis). Arch Pathol Lab Med 1978;102:158-60.

Requests for reprints to: Dr LY Shih, Division of Haematology, Department of Internal Medicine, Chang Gung Memorial Hospital, 199 Tung-Hwa North Road, Taipei, Taiwan, 105. 